\title{
Expression of C1q in the serum of patients with non-severe aplastic anemia, and its association with disease severity
}

\author{
SHAOXUE DING ${ }^{*}$, CHUNYAN LIU*, YANG LI* , HUI LIU, ZHAOYUN LIU, \\ TONG CHEN, TIAN ZHANG, ZONGHONG SHAO and RONG FU
}

\author{
Department of Hematology, Tianjin Medical University General Hospital, Tianjin 300052, P.R. China
}

Received April 23, 2018; Accepted November 13, 2018

DOI: $10.3892 / \mathrm{mmr} .2018 .9754$

\begin{abstract}
A type of aplastic anemia (AA), non-severe aplastic anemia (NSAA) is defined as AA that does not meet the diagnostic criteria of severe aplastic anemia (SAA). Complement component 1q (Clq) has an important role in the pathogenesis of various autoimmune diseases; however, the role of $\mathrm{Clq}$ in the immune pathogenesis of NSAA is not clear. The current study aimed to determine whether $\mathrm{Clq}$ has an important role in the pathogenesis of NSAA. Isobaric tags for relative and absolute quantitation (iTRAQ) was used to compare the protein expression in bone marrow mononuclear cells from patients with NSAA and healthy volunteers. Pathway enrichment analysis was performed to determine the biological functions involved in NSAA. The differential expression of Clq was marked compared with other proteins. Subsequently, the concentration of $\mathrm{Clq}$ in serum samples was determined using ELISA and the correlation of Clq levels and NSAA severity was evaluated. The serum concentrations of Clq were significantly lower in untreated patients with newly diagnosed NSAA compared with NSAA cases in remission and normal controls. Furthermore, there was no significant difference in Clq concentration between newly diagnosed patients with NSAA and patients with autoimmune hemolytic anemia or immune thrombocytopenia. The serum concentration of $\mathrm{Clq}$ in newly diagnosed NSAA was significantly lower in patients with SAA $(\mathrm{P}<0.0001)$; whereas, there was no significant difference between the patients with SAA, patients with NSAA remission and normal controls $(\mathrm{P}>0.05)$. Additionally, the serum Clq concentration was significantly correlated with granulocyte counts, the level of hemoglobin, platelet counts, reticulocyte percentage and remission in patients with NSAA.
\end{abstract}

Correspondence to: Dr Rong Fu, Department of Hematology, Tianjin Medical University General Hospital, 154 Anshan Road, Heping, Tianjin 300052, P.R. China

E-mail: florai@sina.com

*Contributed equally

Key words: non-severe aplastic anemia, complement 1q, isobaric tags for relative and absolute quantitation
The serum C1q concentration was also positively correlated with the myeloid/plasmacytoid dendritic cell ratio, and negatively correlated with the $\mathrm{CD} 4(+) / \mathrm{CD} 8(+)$ ratio. These findings suggested that $\mathrm{Clq}$ may be a reliable serological marker for monitoring and evaluating disease severity in patients with NSAA. Clq may have an important role in the immune pathogenesis of NSAA.

\section{Introduction}

Aplastic anemia (AA) is classified as non-severe aplastic anemia (NSAA), severe aplastic anemia (SAA) and very severe AA, according to the degree of cytopenia. NSAA is defined as AA that does not meet the diagnostic criteria of SAA (1). NSAA is a type of AA, which is a common chronic disease of the blood that severely affects the quality of life of patients; however, current treatments are ineffective and costly $(2,3)$. In previous years, accumulating evidence has indicated that the pathogenesis of AA is associated with the abnormal activation of $\mathrm{T}$ cells, which damages hematopoietic stem cells (HSCs) (4). The clinical course of NSAA is quite variable compared with SAA. As the disease develops, certain patients may progress to SAA. In patients with NSAA, the lower the blood cell counts and reticulocyte percentage (Ret\%), the more readily the disease progresses and the more serious the disease state. Furthermore, patients that do not respond to treatment also readily progress to SAA (5). Approximately one-half to two-thirds of patients with NSAA are expected to respond to oxymetholone, cyclosporine or other agents; however, the remaining one-third of patients will experience treatment failure $(6,7)$. Although some progress has been made in the treatment of NSAA, the current therapeutics are not satisfactory.

The pathogenesis of NSAA is closely associated with immune abnormalities; therefore, NSAA is considered to be an autoimmune disease involving immune-mediated bone marrow hematopoietic damage (8). In the clinic, the majority of patients with NSAA respond well to adrenocortical hormone and/or high-dose intravenous immunoglobulin treatment, indicating that the cytopenia may be mediated by autoantibodies $(9,10)$. There may also be a humoral immune mechanism involved in the pathogenesis of NSAA. However, the precise mechanisms of humoral immune attack on HSCs remain unclear. 
Under physiological conditions, complement activation and the regulation of the system are in equilibrium, and the system protects the organism from pathogens. When the balance is altered, the disorganized complement system attacks its own cells and tissues, causing multiple inflammatory reactions and autoimmune diseases (11). The complement system has a biological role in phagocytosis, clearing senescent cells, the immune response and mediating inflammatory reactions (12). Complement component $1 \mathrm{q}(\mathrm{C} 1 \mathrm{q})$ is an important component of the classical complement cascade and is involved in disassembling immune complexes and removing apoptotic debris (13). It is unclear whether C1q or other components are involved in the pathogenesis of NSAA.

The present study used isobaric tags for relative and absolute quantitation (iTRAQ) technology to identify differently expressed proteins by comparing bone marrow mononuclear cells (BMMNCs) from patients with NSAA and healthy volunteers to investigate the immune mechanisms of NSAA. ELISA was used to measure the concentration of differently expressed proteins in serum samples, and the association between serum protein levels and disease severity in patients with NSAA was evaluated.

\section{Materials and methods}

Patients. For iTRAQ detection, 20 untreated patients newly diagnosed with NSAA were recruited between June 2016 and June 2017 at the Hematology Department of Tianjin Medical University General Hospital (Tianjin, China). Additionally, 20 healthy volunteers, with normal routine blood analyses, were recruited as the normal control group. The characteristics of the patients and normal controls are listed in Tables I and II.

For ELISA detection, blood samples from 80 patients with NSAA were collected at the Hematology Department of Tianjin Medical University General Hospital between January 2017 and June 2017, including 40 newly diagnosed patients and 40 patients in remission following treatment. NSAA was diagnosed according to the International AA Study Group criteria (14). Blood samples from 60 sex and age-matched patients with autoimmune disease were also obtained, including 20 patients with SAA, 20 patients with autoimmune hemolytic anemia (AIHA) and 20 patients with immune thrombocytopenia (ITP) as case controls. Another 20 sex and age-matched healthy controls were also enrolled in the study (Table III). The healthy control cohorts comprised from individuals who had undergone comprehensive medical screening at the Tianjin Medical University General Hospital, with no history of chronic diseases and no family history of autoimmune diseases.

Human blood samples were collected following a protocol approved by the Ethics Committee of the Tianjin Medical University. Written consent was obtained from every individual, according to the protocol of the Ethics Committee for the Conduct of Human Research. For participants $<18$ years of age, written informed consent was obtained from their guardians or parents. Based on the Declaration of Helsinki, informed written consent was obtained from all participants or their guardians.

Extraction of BMMNCs. Firstly, $5 \mathrm{ml}$ fresh bone marrow was collected from each participant, and there were no signs of infection in any samples. No participants had received transfusion of blood or blood products within the 3 days prior to sample collection. BMMNCs were isolated by density gradient centrifugation $\left(750 \mathrm{x}\right.$ g for $20 \mathrm{~min}$ at $20^{\circ} \mathrm{C}$; density, 1.077; Tianjin Hao Yang Biological Products Technology Co., Ltd., Tianjin, China) using Ficoll-Paque Plus solution (GE Healthcare Life Sciences, Uppsala, Sweden).

Protein extraction and quantitative analysis. The collected cells were washed twice with cold PBS and dissolved in lysis buffer ( $2 \mathrm{M}$ thiourea, $7 \mathrm{M}$ urea and $0.1 \% \mathrm{CHAPS}$ ). Sonication was performed (60 sec, $20 \mathrm{kHz}$, amplitude 22\%) and the supernatant was collected, followed by static extraction for $30 \mathrm{~min}$ at room temperature and centrifugation at $15,000 \mathrm{x} \mathrm{g}$ for $20 \mathrm{~min}$ at $4^{\circ} \mathrm{C}$. Finally, the protein concentration was measured using a Bradford assay with bovine serum albumin (Sigma-Aldrich; Merck KGaA, Darmstadt, Germany) as the standard. The remaining samples were stored at $-80^{\circ} \mathrm{C}$.

iTRAQ analysis. First, iTRAQ tagging and analysis was performed. The protein from each sample was reduced, alkylated and digested with trypsin. The digested peptides were dried and reconstituted in $50 \mu 11 \mathrm{M}$ triethylammonium bicarbonate. The dried peptides were labeled following the manufacturer's protocols (iTRAQ 8-plex kits; AB Sciex LLC, Framingham, MA, USA). Second, all the labelled peptides were pooled together followed by the separation of fractions using reversed-phase liquid chromatography which was performed by a RIGOL L-3000 system (RIGOL Technologies, Inc., Beijing, China). Then the fractionated peptides were analyzed using a Q-Exactive mass spectrometer (Thermo Fisher Scientific, Inc., Waltham, MA, USA) fitted with a nano-liquid chromatography system. Then Proteome Discoverer software version 1.3 (Thermo Fisher Scientific, Inc.) was used to interpret the data files. The files were searched using the Mascot search engine against the human protein database downloaded from NCBI (www.ncbi.nlm.nih.gov, Refseq. Human.20130704. fasta).

Kyoto Encyclopedia of Genes and Genomes (KEGG) pathway enrichment analysis. In order to ascertain the biological functions of proteins exhibiting a significant difference in expression levels, proteins were functionally annotated according to the Gene Ontology Consortium database (http://www.geneontology.org/) in order to perform gene ontology (GO) annotation and enrichment analysis. Pathway analysis was also used to determine the significant pathways of the differentially expressed genes using the pathway annotations of microarray genes downloaded from KEGG (http://www.genome.p/kegg).

Detection of serum Clq. All sera were treated with heparin and frozen in $100 \mu \mathrm{l}$ aliquots at $-80^{\circ} \mathrm{C}$ prior to analysis. There were no genetic relationships between the study participants. All the samples were collected with informed consent. The concentration of serum Clq was measured using a commercially available ELISA kit (cat. no. SEA747Hu) according to the manufacturer's instructions (Cloud-Clone Corp., Wuhan, China). Briefly, the serum was diluted 1:5,000, and the ELISA plate wells were divided into diluted standards, blank and sample wells, with seven wells as standards and one well as the blank. Dilutions of 
Table I. Characteristics of patients with untreated non-severe aplastic anemia.

\begin{tabular}{|c|c|c|c|c|c|c|}
\hline Case & Age/sex & $\begin{array}{l}\text { Granulocyte } \\
\left(\times 10^{9} / 1\right)\end{array}$ & $\begin{array}{c}\text { Hemoglobin } \\
(\mathrm{g} / \mathrm{l})\end{array}$ & $\begin{array}{l}\text { Platelet } \\
\left(\mathrm{x} 10^{9} / 1\right)\end{array}$ & Ret $\%$ & $\begin{array}{c}\text { Abnormal } \\
\text { chromosome }\end{array}$ \\
\hline 1 & 19/M & 1.45 & 88 & 19 & 1.18 & Absent \\
\hline 2 & $71 / \mathrm{M}$ & 1.72 & 94 & 23 & 1.69 & Absent \\
\hline 3 & $38 / \mathrm{F}$ & 0.55 & 75 & 44 & 1.78 & Absent \\
\hline 4 & 47/M & 0.67 & 78 & 51 & 1.53 & Absent \\
\hline 5 & $62 / \mathrm{M}$ & 0.58 & 76 & 18 & 1.17 & Absent \\
\hline 6 & $55 / \mathrm{F}$ & 1.04 & 82 & 62 & 1.37 & Absent \\
\hline 7 & $77 / F$ & 1.16 & 84 & 25 & 1.75 & Absent \\
\hline 8 & $12 / \mathrm{M}$ & 0.78 & 80 & 20 & 1.34 & Absent \\
\hline 9 & $15 / F$ & 0.71 & 79 & 13 & 1.02 & Absent \\
\hline 10 & $28 / F$ & 0.65 & 69 & 38 & 0.62 & Absent \\
\hline 11 & $44 / \mathrm{M}$ & 0.98 & 80 & 42 & 0.85 & Absent \\
\hline 12 & $57 / \mathrm{M}$ & 0.91 & 79 & 26 & 1.45 & Absent \\
\hline 13 & $62 / F$ & 0.86 & 90 & 47 & 1.98 & Absent \\
\hline 14 & $53 / \mathrm{M}$ & 0.72 & 69 & 33 & 0.67 & Absent \\
\hline 15 & $24 / F$ & 1.34 & 92 & 25 & 2.05 & Absent \\
\hline 16 & $38 / \mathrm{M}$ & 1.29 & 83 & 56 & 1.72 & Absent \\
\hline 17 & $39 / \mathrm{F}$ & 1.04 & 79 & 69 & 1.07 & Absent \\
\hline 18 & 47/M & 1.86 & 84 & 78 & 1.76 & Absent \\
\hline 19 & $9 / \mathrm{F}$ & 1.22 & 85 & 44 & 1.65 & Absent \\
\hline 20 & $50 / \mathrm{M}$ & 0.62 & 70 & 29 & 0.75 & Absent \\
\hline
\end{tabular}

M, male; F, female; Ret $\%$, reticulocyte percentage.

standards, blank and samples $(100 \mu \mathrm{l})$ were added to the corresponding wells. The plate was covered with a plate sealer and incubated for $1 \mathrm{~h}$ at $37^{\circ} \mathrm{C}$. Subsequently, the liquid was removed from each well and $100 \mu$ l Detection Reagent A working solution was added to each well. The wells were covered with a plate sealer and incubated for $1 \mathrm{~h}$ at $37^{\circ} \mathrm{C}$, followed by washing three times. Subsequently, $100 \mu$ l Detection Reagent B working solution was added to each well and incubated for $1 \mathrm{~h}$ at $37^{\circ} \mathrm{C}$, followed by three washes. Finally, $90 \mu \mathrm{l}$ Substrate Solution was added to each well and incubated for $20 \mathrm{~min}$ at $37^{\circ} \mathrm{C}$. The liquid turned blue following the addition of Substrate Solution and the optical density (OD) was measured spectrophotometrically at a wavelength of $450 \pm 10 \mathrm{~nm}$. The concentration of Clq in the samples was determined by comparing the OD of the samples to the standard curve.

Measurement of complete blood count $(C B C)$ of peripheral blood. CBC assessment is critical not only for diagnosing and managing NSAA, but also for assessing disease severity. The following CBC parameters were studied: Granulocyte counts; platelet counts; the level of hemoglobin; and Ret\%. All CBCs were performed using Sysmex XE-2100 (Sysmex Corporation, Kobe, Japan).

Measurement of $T$ cell subsets (CD4/CD 8 ratio) and dendritic cell subsets $(\mathrm{mDC} / \mathrm{pDC}$ ratio) in peripheral blood by flow cytometry. Cluster of differentiation (CD)3(+) CD4(+) and CD3(+)CD8(+) T lymphocytes were stained using anti-CD3-peridinin chlorophyll protein complex
(PerCP), anti-CD4-fluorescein isothiocyanate (FITC) and anti-CD8-phycoerythrin (PE). Myeloid dendritic cells (mDCs) were identified as Lin(-) major histocompatibility complex, class II, DR (HLA-DR)(+)CD11c(+), while plasmacytoid dendritic cells (pDCs) were identified as Lin(-)HLA-DR(+) CD123(+). The cells were incubated for $30 \mathrm{~min}$ at $4^{\circ} \mathrm{C}$ with the antibodies. CD3-PerCP (cat. no. 552851; $20 \mu \mathrm{l}$ ), CD4-FITC (cat. no. 340133; $20 \mu 1$ ), CD8-PE (cat. no. 340046; $20 \mu 1$ ), Lin-FITC (cat. no. 562722; $20 \mu 1$ ), HLA-DR-PerCP (cat. no. 347364; $20 \mu \mathrm{l}$ ), CD123-PE (cat. no. 554529; dilution, $0.2 \mathrm{mg} / \mathrm{ml}$ ), and CD11c-APC (cat. no. 559877; $20 \mu \mathrm{l}$ ) antibodies were purchased from BD Pharmingen (BD Biosciences, San Jose, CA, USA). All the antibodies detected by flow cytometry were directly immunofluorescent labelled, therefore a secondary antibody was not required. The data collected in the experiment were analyzed using a BD FACSCalibur (BD Biosciences) with CellQuest software, version 3.1.

Statistical analysis. All data were analyzed using Prism software (version 6; GraphPad Software, Inc., La Jolla, CA, USA) and/or SPSS for Windows (version 19.0; IBM Corp., Armonk, NY, USA). The significance of comparisons between means was determined with multiple t-tests using the Holm-Sidak method, and one-way analysis of variance when a Gaussian distribution was assumed or Kruskal-Wallis test when a Gaussian distribution was not assumed. The association between qualitative variables was evaluated by Spearman correlation analysis. Data are presented as the mean \pm standard deviation. All experiments were performed 
Table II. Characteristics of normal controls.

\begin{tabular}{|c|c|c|c|c|c|c|}
\hline Case & Age/sex & $\begin{array}{l}\text { Granulocyte } \\
\left(\times 10^{9} / 1\right)\end{array}$ & $\begin{array}{l}\text { Hemoglobin } \\
(\mathrm{g} / \mathrm{l})\end{array}$ & $\begin{array}{l}\text { Platelet } \\
\left(\mathrm{x} 10^{9} / 1\right)\end{array}$ & Ret\% & $\begin{array}{c}\text { Abnormal } \\
\text { chromosome }\end{array}$ \\
\hline 1 & $22 / \mathrm{M}$ & 2.45 & 135 & 357 & 1.96 & Absent \\
\hline 2 & 69/M & 2.72 & 140 & 256 & 1.49 & Absent \\
\hline 3 & $39 / \mathrm{F}$ & 3.25 & 125 & 44 & 1.58 & Absent \\
\hline 4 & 49/M & 2.67 & 162 & 251 & 1.33 & Absent \\
\hline 5 & $41 / \mathrm{M}$ & 3.58 & 136 & 219 & 1.47 & Absent \\
\hline 6 & $51 / \mathrm{F}$ & 2.98 & 145 & 199 & 1.17 & Absent \\
\hline 7 & $71 / \mathrm{F}$ & 3.24 & 136 & 262 & 1.75 & Absent \\
\hline 8 & $15 / \mathrm{M}$ & 2.76 & 143 & 310 & 1.09 & Absent \\
\hline 9 & $19 / \mathrm{F}$ & 2.62 & 139 & 215 & 1.31 & Absent \\
\hline 10 & $21 / \mathrm{F}$ & 2.44 & 148 & 148 & 1.53 & Absent \\
\hline 11 & $41 / \mathrm{M}$ & 3.71 & 142 & 301 & 1.08 & Absent \\
\hline 12 & $52 / \mathrm{M}$ & 2.76 & 135 & 217 & 1.17 & Absent \\
\hline 13 & $63 / F$ & 2.41 & 131 & 281 & 1.29 & Absent \\
\hline 14 & $51 / \mathrm{M}$ & 2.10 & 139 & 219 & 1.41 & Absent \\
\hline 15 & $29 / F$ & 2.86 & 122 & 187 & 1.61 & Absent \\
\hline 16 & $33 / \mathrm{M}$ & 2.35 & 141 & 281 & 1.51 & Absent \\
\hline 17 & $42 / F$ & 3.11 & 115 & 156 & 1.11 & Absent \\
\hline 18 & 41/M & 2.88 & 143 & 198 & 1.42 & Absent \\
\hline 19 & $20 / F$ & 3.22 & 128 & 189 & 1.66 & Absent \\
\hline 20 & $51 / \mathrm{M}$ & 3.10 & 141 & 178 & 1.21 & Absent \\
\hline
\end{tabular}

M, male; F, female; Ret $\%$, reticulocyte percentage.

Table III. Characteristics of the patients who provided the sera.

\begin{tabular}{lccr}
\hline Patient group & $\begin{array}{c}\text { No. } \\
\text { patients }\end{array}$ & $\begin{array}{c}\text { Age (years), } \\
\text { median (range) }\end{array}$ & $\begin{array}{r}\text { Sex, } \\
\text { M/F }\end{array}$ \\
\hline Untreated NSAA & 40 & $40(17-62)$ & $19 / 21$ \\
Remission NSAA & 40 & $36(16-70)$ & $18 / 22$ \\
Normal controls & 20 & $37(20-71)$ & $11 / 9$ \\
AIHA & 20 & $33(18-79)$ & $9 / 11$ \\
SAA & 20 & $34(11-68)$ & $8 / 12$ \\
ITP & 20 & $30(15-72)$ & $11 / 9$ \\
\hline
\end{tabular}

M, male; F, female; NSAA, non-severe aplastic anemia; ITP, immune thrombocytopenia; AIHA, autoimmune hemolytic anemia; SAA, severe aplastic anemia.

in duplicate. $\mathrm{P}<0.05$ was considered to indicate a statistically significant difference.

\section{Results}

iTRAQ analysis of the differential expression of $\mathrm{Clq}$ in patients with NSAA compared with healthy participants. iTRAQ is an in vitro isotope labeling technique that is high-throughput, highly sensitive, and is able to provide relative or absolute protein quantification of four or eight samples. In order to identify proteins associated with the pathogenesis of NSAA, a comparative analysis of BMMNC proteomics was performed in patients with NSAA and a control group using iTRAQ. Cutoff values of 0.404-fold for underexpression and 2.612-fold for overexpression were used to define a differentially expressed protein according to a $95 \%$ confidence level. Using these criteria, 134 proteins were differentially expressed between patients with NSAA and normal controls. Among the differentially expressed proteins, 42 were upregulated and 92 were downregulated in patients with NSAA compared with the normal controls. Kyoto Encyclopedia of Genes and Genomes pathway enrichment analysis revealed that the differentially expressed proteins were enriched in a number of pathways, including 'complement protein', 'MHC II', 'H2A histone family', 'H3 histone', 'histone cluster 1' and 'histone cluster 1' (Table IV); however, expression of these proteins was only significantly enriched one pathway, 'Non-severe aplastic anemia', mainly about 'Humoral immune pathogenesis' $(\mathrm{P}<0.05$; Table V). Specifically, the differential expression of $\mathrm{C} 1 \mathrm{q}$ was more marked compared with the other proteins, with the expression of Clq being lower in patients with NSAA compared with normal controls. This suggested that C1q may have an important role in the pathogenesis of NSAA (Fig. 1).

Serum levels of $\mathrm{Clq}$ in each group of patients. In order to validate the results of iTRAQ, the Clq concentration was measured in serum samples from patients with untreated NSAA, NSAA in remission, SAA, ITP and AIHA, and healthy individuals. Serum concentrations of Clq were 26.99 \pm 20.94 , $47.54 \pm 38.56,41.13 \pm 22.85,20.71 \pm 13.45,15.04 \pm 8.18$ and 
Table IV. Data on seven differentially expressed proteins in the 'non-severe aplastic anemia' pathway.

\begin{tabular}{llll}
\hline Accession no. & & \multicolumn{1}{c}{ Gene name } & Related genes \\
\hline 29553970 & H2A histone family, member J & RG & Homo sapiens \\
4885385 & H3 histone, family 3B (H3.3B); H3 histone, family 3A & RG & Homo sapiens \\
& pseudogene; H3 histone, family 3A; similar to H3 histone, & \\
166235903 & family 3B; similar to histone H3.3B & RG \\
45580688 & Complement component 1, q subcomponent, C chain & RG & Homo sapiens \\
18105048 & Complement component 7 & RG & Homo sapiens \\
24638446 & Histone cluster 1, H2bk & RG & Homo sapiens \\
52630344 & Histone cluster 2, H2ac & RG & Homo sapiens \\
& Major histocompatibility complex, class II, DR $\beta 4 ;$ major & Homo sapiens
\end{tabular}

RG, related gene.

Table V. Data on two pathways in the KEGG enrichment analysis.

\begin{tabular}{|c|c|c|c|c|c|}
\hline Category & Term & Count & $\%$ & P-value & Benjamini \\
\hline KEGG_PATHWAY & Non-severe aplastic anemia & 7 & 5.6 & $3.00 \times 10^{-4}$ & $2.40 \times 10^{-2}$ \\
\hline KEGG_PATHWAY & Lysosome & 4 & 3.2 & $9.70 \times 10^{-2}$ & $9.80 \times 10^{-1}$ \\
\hline
\end{tabular}

KEGG, Kyoto Encyclopedia of Genes and Genomes.

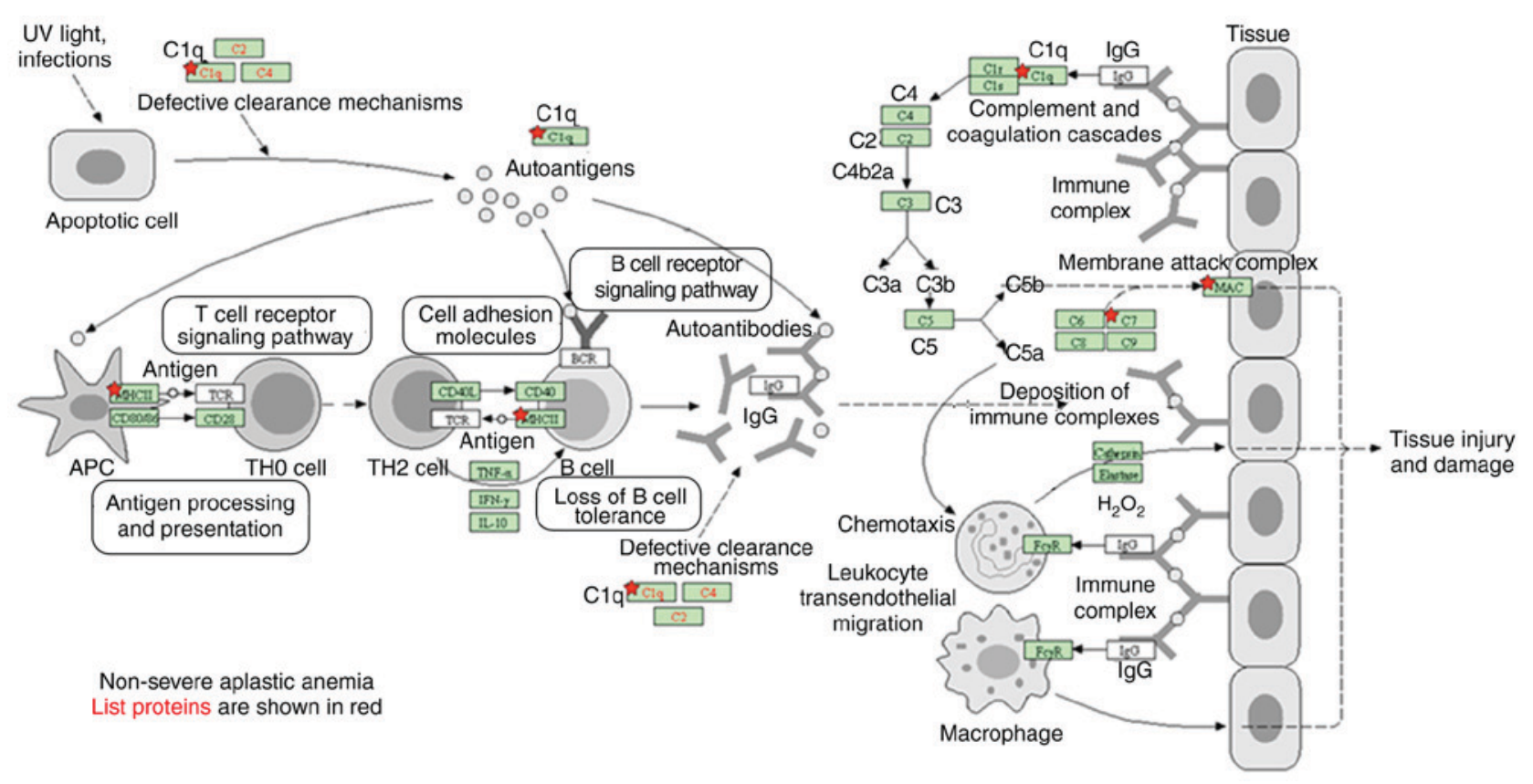

Figure 1. Kyoto Encyclopedia of Genes and Genomes pathway analysis of differentially expressed proteins. The differential expression of Clq is more obvious in patients NSAA compared with normal controls. Red stars represent differentially expressed proteins. Clq, complement component 1q; NSAA, non-severe aplastic anemia.

$45.14 \pm 25.87 \mu \mathrm{g} / \mathrm{ml}$, in patients with untreated NSAA, patients with NSAA in remission, patients with SAA, ITP and AIHA, and normal controls, respectively. The concentrations of $\mathrm{Clq}$ in the untreated patients with NSAA, and patients with ITP or AIHA were significantly lower compared with those in healthy individuals $(\mathrm{P}=0.005, \mathrm{P}=0.0009$ and $\mathrm{P}<0.0001$, respectively). The concentration of C1q in the untreated patients with NSAA was significantly lower compared with that in patients with SAA $(\mathrm{P}<0.0001)$; however, there was no significant difference among patients with SAA, NSAA in remission and normal 


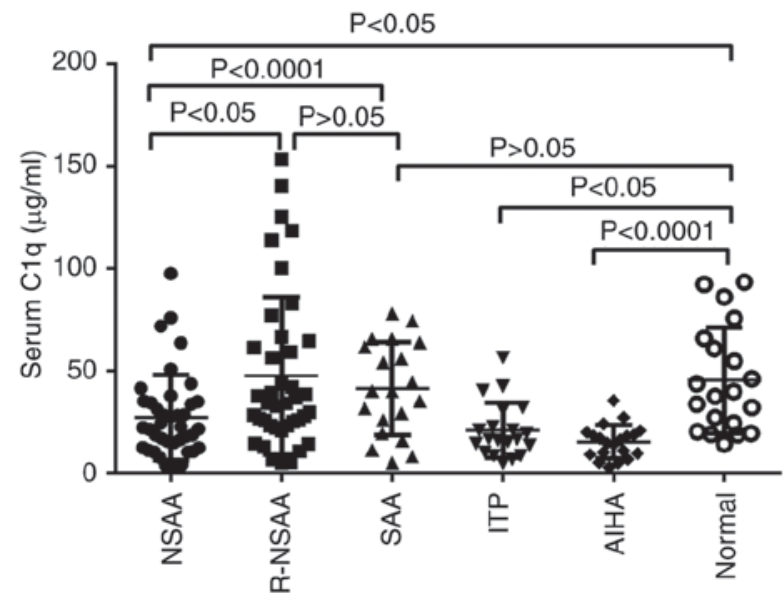

Figure 2. Serum levels of C1q in each group of patients. The concentrations of C1q in the untreated patients with NSAA, and patients with ITP or AIHA were significantly lower compared with those in the healthy individuals, and the $\mathrm{Clq}$ in the untreated patients with NSAA was significantly lower compared with patients with SAA. The serum C1q levels of the patients with NSAA in remission were higher compared with those of the untreated patients; however, there was no statistical difference among patients with NSAA in remission, SAA and normal controls. NSAA, untreated non-severe aplastic anemia; R-NSAA, non-severe aplastic anemia remission; C1q, complement component 1q; ITP, immune thrombocytopenia; AIHA, autoimmune hemolytic anemia.

controls $(\mathrm{P}>0.05)$. The serum $\mathrm{Clq}$ levels of the patients with NSAA in remission were higher compared with those of the untreated patients; however, there was no statistical difference between patients with NSAA in remission and normal controls (P>0.05; Fig. 2).

Correlations of serum levels of $\mathrm{Cl} q$ and clinical indicators in patients with untreated NSAA. In order to understand the clinical significance of C1q in NSAA, the association between $\mathrm{Clq}$ levels in serum and the clinical indicators of NSAA was determined by correlation analysis. The clinical indicators analyzed included blood cell counts (granulocytes, hemoglobin, platelets and Ret\%) and immune indices (mDC/pDC and CD4/CD8 ratio). The serum concentrations of $\mathrm{Clq}$ were positively correlated with granulocyte counts $(\mathrm{r}=0.792 ; \mathrm{P}<0.0001)$, hemoglobin $(\mathrm{r}=0.602 ; \mathrm{P}<0.0001)$, platelet counts $(\mathrm{r}=0.716 ; \mathrm{P}<0.0001)$ and $\mathrm{Ret} \%(\mathrm{r}=0.845$; $\mathrm{P}<0.0001)$. Additionally, the serum $\mathrm{Clq}$ concentration was positively correlated with the $\mathrm{mDC} / \mathrm{pDC}$ ratio $(\mathrm{r}=0.749$; $\mathrm{P}<0.01)$ and negatively associated with the $\mathrm{CD} 4 / \mathrm{CD} 8$ ratio ( $\mathrm{r}=-0.621 ; \mathrm{P}<0.0001$; Fig. 3).

\section{Discussion}

NSAA is a common chronic disease of the blood that seriously affects the quality of life of patients, and the current treatments are not effective $(2,3)$. Years of research have revealed that the pathogenesis of NSAA is closely associated with immune abnormalities (8). In our previous clinical research, patients diagnosed with NSAA received experimental administration of corticosteroids and/or high-dose $\gamma$ globulin and, after 3 months of follow-up, all patients exhibited a marked response to treatment $(9,10)$. Previous reports have suggested that the incidence of this disease may be associated with abnormal humoral immunity $(9,10)$. Wang et al $(9)$ reported that immune-related hemocytopenia (BMMNC-Coombs test-positive hemocytopenia) is an autoimmune disease in which autoantibodies target bone marrow hemopoietic cells, and the autoantibodies are detectable by BMMNC-Coombs test or flow cytometry. Additionally, certain patients with systemic lupus erythematosus (SLE) that have cytopenia are BMMNC-Coombs positive (15). These results suggest that humoral immunity is involved in the pathogenesis of NSAA.

In recent years, proteome research technology has been widely used in numerous fields of medical science, and remarkable achievements have been reported in autoantigen isolation and identification techniques, which have facilitated basic research into autoimmune diseases (16). iTRAQ technology is an in vitro isotope labeling technique developed in recent years, and it has been widely used in quantitative differential proteomics analysis, particularly in the investigation of tumor and autoimmune diseases (17). iTRAQ is one of the most recently developed of these high-throughput, high-sensitivity techniques that are able to perform relative or absolute quantification of protein expression levels. One of the advantages of the technology is that it is able to detect proteins in samples of $\geq 100 \mu \mathrm{g}(18,19)$. The iTRAQ method is more sensitive and reliable compared with previous proteomic techniques. The advantages of iTRAQ facilitated the proteomic investigation of BMMNCs from patients with NSAA in the current study.

Serada and Naka (20) previously screened for novel biomarkers in patients with rheumatoid arthritis (RA) using iTRAQ technology. The marker identified may be useful for assessing disease activity in patients with rheumatoid arthritis (RA) following the use of anti-tumor necrosis factor- $\alpha$ therapy, and may help to evaluate disease prognosis in patients with RA (20). To further investigate the pathogenesis of NSAA, iTRAQ technology was used in the current study to compare the protein expression in mononuclear cells obtained from patients with NSAA and normal subjects.

The results revealed that the expression of various proteins was different in patients with NSAA compared with normal subjects. Pathway analysis demonstrated that the expression of proteins associated with the humoral immune pathway was abnormal in patients with NSAA compared with normal controls. Thus, the pathogenesis of NSAA may be associated with specific antigen stimulation leading to the activation of antigen presenting cells and the transformation of TH0 cells into TH2 cells, which activates B cells to produce antibodies, and ultimately destroys hematopoietic cells in the bone marrow. This supports our previous study of the pathogenesis of NSAA $(9,10)$, and suggests that the complement system has an important role in NSAA. The complement system is an important component of innate immunity consisting of a group of proteins with enzyme activity that functions in the blood and on the surface of blood cells. The complement system has an important role in immune responses and in mediating inflammatory reactions (12), and may be activated through three pathways (21). The classical pathway of complement activation is characterized by the binding of Clq to immune complexes (22). C1q complexes contain proteins encoded by three genes, $\mathrm{ClqA}, \mathrm{ClqB}$ and $\mathrm{ClqC}$, localized at chromosome 1p34-36 (23). It is an important component of the classical 

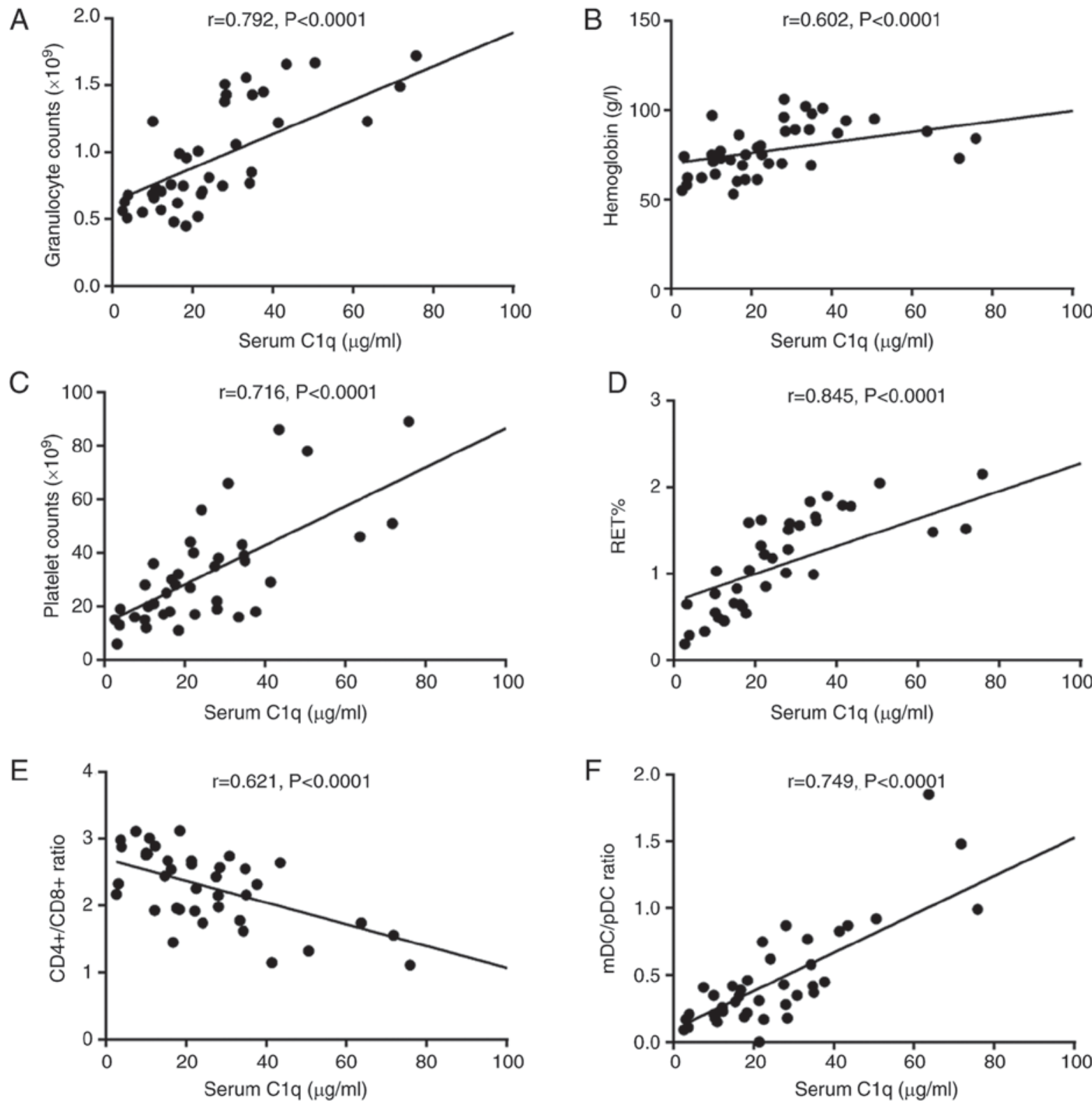

Figure 3. Correlations of serum Clq levels and clinical indicators in untreated patients with non-severe aplastic anemia. (A) Correlation between the serum levels of $\mathrm{Clq}$ and the granulocyte count. (B) Correlation between the serum levels of Clq and the level of hemoglobin. (C) Correlation between the serum levels of Clq and the platelet counts. (D) Correlation between the serum levels of Clq and Ret\%. (E) Correlation between the serum levels of Clq and $\mathrm{T}$ cells subsets (CD4 ${ }^{+} / \mathrm{CD}^{+}$ratios). (F) Correlation between the serum levels of $\mathrm{Clq}$ and dendritic cell subsets (DC1/DC2 ratios). Clq, complement component 1q; Ret\%, reticulocyte percentage; CD, cluster of differentiation; DC, dendritic cell.

complement pathway and is involved in disassembling immune complexes and removing apoptotic debris (13).

When the complement system is in equilibrium it protects the organism from pathogens. When the balance is disrupted, the complement system may attack cells and tissues, causing multiple inflammatory reactions and autoimmune diseases (11). The complement system is activated via the classical pathway, alternative pathway, or mannose-binding lectin pathway. $\mathrm{C} 1 \mathrm{q}$ is an important mediator of the classical complement pathway, and it clears antigen antibody complexes by identifying the complement binding site of the antibody Fc segment in the $\mathrm{IgG}$ or $\operatorname{IgM}$ immune complex to activate the complement cascade (24). Additionally, recent research has indicated that $\mathrm{Clq}$ is able to identify apoptotic cells via a complement-dependent immune regulation pathway, with $\mathrm{C} 1 \mathrm{q}$ rapidly initiating phagocytosis to eliminate apoptotic cells (25). Clq also inhibits inflammatory responses and helps the body maintain its immune tolerance. Alsuwaida et al (26) detected Clq levels in serum from patients with SLE, and the results indicated that C1q levels were lower in patients with SLE compared with other rheumatic diseases, patients with kidney disease and a normal control group. Correlation analysis revealed that serum $\mathrm{Clq}$ levels in patients with SLE were negatively correlated with SLE disease activity index scores. These previous findings suggested that detecting serum Clq may be useful for the diagnosis of SLE and lupus nephritis, and may be an important indicator for evaluating SLE disease severity and assessing the potential curative effect of treatments. The pathogenesis of SLE is associated with loss-of-function C1q mutations in 
numerous patients (27-29). Additionally, decreased activity of C1q in the classical pathway is associated with the severity of SLE. The presence of anti-C1q autoantibodies may result in decreased C1q levels in patients with SLE (30). Another study that detected serum levels of complement $\mathrm{C} 1 \mathrm{q}$ in patients with RA (active and remission groups) and healthy subjects demonstrated that the level of Clq in the active RA group was significantly higher compared with that in the RA remission group and healthy control group, indicating that C1q is associated with RA activity and may be used as an evaluation index to assess disease status (31). In the current study, 134 proteins were significantly differentially expressed between patients with NSAA and normal controls. Among the differentially expressed proteins, 42 were upregulated and 92 were downregulated. In the protein screening analysis, the differential expression of C1q was more marked in patients with NSAA compared with normal controls. Subsequently, ELISA was used to validate the proteomics data and the findings confirmed that $\mathrm{Clq}$ levels were significantly lower in patients with NSAA compared with normal controls, and the level of C1q was significantly correlated with the immune status of the patients. Patients with SAA, AIHA and ITP were used as case controls, and the C1q levels in patients with ITP and AIHA were significantly lower compared with those in normal controls. The concentration of C1q in the untreated patients with NSAA was significantly lower compared with that in patients with SAA; however, there was no significant difference among patients with SAA, patients with NSAA remission and normal controls. These results suggested that the complement pathway may have an important role in the pathogenesis of NSAA.

In conclusion, NSAA is an autoimmune disease mediated by immune hyperfunction that targets the hematopoietic system. Previous clinical work suggested that patients with NSAA have abnormal humoral immune function $(9,10)$. The current study used iTRAQ technology to demonstrate that abnormal humoral immune mechanisms are present in patients with NSAA. In the current study, iTRAQ data suggested that C1q has a role in the immune pathogenesis of NSAA, which may be associated with the hyperfunction of immune responses and the immunological destruction of HSCs. The complement pathway serves an important role in the pathogenesis of NSAA, and the specific mechanisms involved require further investigation. Balancing the stability of complement components may be a potential new direction for research into and treatment for NSAA.

\section{Acknowledgements}

The authors would like to thank the staff of the Department of Hematology, Tianjin Medical University General Hospital (Tianjin, China) for their support.

\section{Funding}

The present study was supported by the Natural Science Foundation of China (grant nos. 81770110, 81570106, 81600088, 81600093 and 81400085$)$ and Tianjin Chronic Disease Prevention and Control Science and Technology Special Project (grant no. 16ZXMJSY00180).

\section{Availability of data and materials}

The datasets used and/or analyzed during the current study are available from the corresponding author on reasonable request.

\section{Authors' contributions}

CL, HL, ZL, TC and TZ conceived and designed the study. SD and YL performed the experiments and were major contributors in writing the manuscript. ZS analyzed and interpreted the data. RF conceived the study, participated in its design and coordination and helped to draft the manuscript. All authors read and approved the final manuscript.

\section{Ethics approval and consent to participate}

The study complied with the Declaration of Helsinki and was approved by the Ethics Committee of Tianjin Medical University General Hospital. Informed written consent was obtained.

\section{Patient consent for publication}

Not applicable.

\section{Competing interests}

The authors declare that they have no competing interests.

\section{References}

1. Camitta BM, Thomas ED, Nathan DG, Santos G, Gordon-Smith EC, Gale RP, Rappeport JM and Storb R: Severe aplastic anemia: A prospective study of the effect of early marrow transplantation on acute mortality. Blood 48: 63-70, 1976.

2. Boddu PC and Kadia TM: Updates on the pathophysiology and treatment of aplastic anemia: A comprehensive review. Expert Rev Hematol 10: 433-448, 2017.

3. Bacigalupo A: How I treat acquired aplastic anemia. Blood 129: 1428-1436, 2017.

4. Dezern AE and Brodsky RA: Clinical management of aplastic anemia. Expert Rev Hematol 4: 221-230, 2011.

5. Kwon JH, Kim I, Lee YG, Koh Y, Park HC, Song EY, Kim HK, Yoon SS, Lee DS, Park SS, et al: Clinical course of non-severe aplastic anemia in adults. Int J Hematol 91: 770-775, 2010.

6. Young NS: Current concepts in the pathophysiology and treatment of aplastic anemia. Hematology Am Soc Hematol Educ Program 2013: 76-81, 2013.

7. Brodsky RA and Jones RJ: Aplastic anaemia. Lancet 365: 1647-1656, 2005.

8. Stanley N, Olson TS and Babushok DV: Recent advances in understanding clonal haematopoiesis in aplastic anaemia. Br J Haematol 177: 509-525, 2017.

9. Wang YH, Fu R, Dong SW, Liu H and Shao ZH: Erythroblastic islands in the bone marrow of patients with immune-related pancytopenia. PLoS One 9: e95143, 2014.

10. Liu H, Fu R, Li L, Ding K, Wang Y, Wang H, Zhang T, Wang G, Song J and Shao Z: Erythropoietin receptors and IgG autoantibody expression on nucleated erythrocytes in some cases of immuno-related pancytopenia. Clin Lab 61: 693-698, 2015.

11. Thurman JM, Frazer-Abel A and Holers VM: The evolving landscape for complement therapeutics in rheumatic and autoimmune diseases. Arthritis Rheumatol 69: 2102-2113, 2017.

12. Ballanti E, Perricone C, Greco E, Ballanti M, Di Muzio G, Chimenti MS and Perricone R: Complement and autoimmunity. Immunol Res 56: 477-491, 2013.

13. Sontheimer RD, Racila E and Racila DM: C1q: Its functions within the innate and adaptive immune responses and its role in lupus autoimmunity. J Invest Dermatol 125: 14-23, 2005. 
14. Marsh JC, Ball SE, Cavenagh J, Darbyshire P, Dokal I, Gordon-Smith EC, Keidan J, Laurie A, Martin A, Mercieca J, et al: Guidelines for the diagnosis and management of aplastic anaemia. Br J Haematol 147: 43-70, 2009.

15. Fu R, Uehara T, Gong L and Shao ZH: Study on the pathogenesis of blood cytopenia in patients with systemic lupus erythematosus. Zhonghua Xue Ye Xue Za Zhi 29: 48-51, 2008 (In Chinese)

16. Moore CD, Ajala OZ and Zhu H: Applications in high-content functional protein microarrays. Curr Opin Chem Biol 30: 21-27, 2016.

17. Ardekani AM, Akhondi MM and Sadeghi MR: Application of genomic and proteomic technologies to early detection of cancer. Arch Iran Med 11: 427-434, 2008.

18. Sui W, Tang D, Zou T, Zou G, Chen J, Li H, Li L, Hou Y, Li H and Dai Y: Differential proteomic analysis of renal tissue in mesangial proliferative glomerulonephritis using iTRAQ technology. J Nephrol 26: 191-198, 2013.

19. Thomas SN, Zhang H and Cotter RJ: Application of quantitative proteomics to the integrated analysis of the ubiquitylated and global proteomes of xenograft tumor tissues. Clin Proteomics 12: $14,2015$.

20. Serada $S$ and Naka T: Screening for novel serum biomarker for monitoring disease activity in rheumatoid arthritis using iTRAQ technology-based quantitative proteomic approach. Methods Mol Biol 1142: 99-110, 2014.

21. Fujita T, Matsushita M and Endo Y: The lectin-complement pathway-its role in innate immunity and evolution. Immunol Rev 198: 185-202, 2004.

22. Duncan AR and Winter G: The binding site for Clq on $\mathrm{IgG}$. Nature 332: 738-740, 1988.

23. Sellar GC, Blake DJ and Reid KB: Characterization and organization of the genes encoding the A-, B- and C-chains of human complement subcomponent C1q. The complete derived amino acid sequence of human C1q. Biochem J 274: 481-490, 1991.
24. Tsang-A-Sjoe MWP, Bultink IEM, Korswagen LA, van der Horst A, Rensink I, de Boer M, Hamann D, Voskuyl AE and Wouters D: Comprehensive approach to study complement C4 in systemic lupus erythematosus: Gene polymorphisms, protein levels and functional activity. Mol Immunol 92: 125-131, 2017.

25. Ghebrehiwet B, Hosszu KH and Peerschke EI: C1q as an autocrine and paracrine regulator of cellular functions. Mol Immunol 84: 26-33, 2017.

26. Alsuwaida A, Husain S, Al Ghonaim M, Aloudah N, Ullah A and Kfoury H: Prognostic significance of Clq deposition in serial biopsies for predicating the long-term outcome in patients with proliferative lupus nephritis. Saudi J Kidney Dis Transpl 27: 305-311, 2016.

27. Botto $\mathrm{M}$ and Walport MJ: C1q, autoimmunity and apoptosis. Immunobiology 205: 395-406, 2002.

28. Pickering MC, Botto M, Taylor PR, Lachmann PJ and Walport MJ: Systemic lupus erythematosus, complement deficiency, and apoptosis. Adv Immunol 76: 227-324, 2000.

29. Schejbel L, Skattum L, Hagelberg S, Åhlin A, Schiller B, Berg S, Genel F, Truedsson L and Garred P: Molecular basis of hereditary Clq deficiency-revisited: Identification of several novel disease-causing mutations. Genes Immun 12: 626-634, 2011.

30. Buyon J, Furie R, Putterman C, Ramsey-Goldman R, Kalunian K, Barken D, Conklin J and Dervieux T: Reduction in erythrocyte-bound complement activation products and titres of anti-C1q antibodies associate with clinical improvement in systemic lupus erythematosus. Lupus Sci Med 3: e000165, 2016.

31. Gilliam BE, Reed MR, Chauhan AK, Dehlendorf AB and Moore TL: Significance of complement components C1q and C4 bound to circulating immune complexes in juvenile idiopathic arthritis: Support for classical complement pathway activation. Clin Exp Rheumatol 29: 1049-1056, 2011.

(i) (9) This work is licensed under a Creative Common cc. $\mathrm{EY}$ NG ND Attribution-NonCommercial-NoDerivatives 4.0 International (CC BY-NC-ND 4.0) License. 